\title{
Esporte e artes plásticas em Portugal: Amadeo de Souza-Cardoso
}

Victor Andrade de Melo

https://doi.org/10.5628/rpcd.10.01.191
Universidade Federal do Rio de Janeiro

Brasil

\section{ABSTRACT}

Sport and art in Portugal: Amadeo de Souza-Cardoso

This study aimed to discuss the presence of sports in the work of Amadeo de Souza-Cardoso, recognized as one of the first Portuguese artists who were tuned with the European vanguards of the pre-First World War. We argue that the characteristics of the work of SouzaCardoso are a good key to understand the relationship between sport, art and society in Portugal in the transition of the XIX ${ }^{\text {th }}$ and XX ${ }^{\text {th }}$ centuries.

Key-words: sport history, art, Amadeo de Souza-Cardoso 


\section{INTRODUÇÃO}

Em estudo recentemente concluído, Melo(15) argumenta que a representação do esporte em obras de arte é notável a partir do momento em que o campo artístico passa a denotadamente melhor expressar o conjunto de mudanças que marca a construção do imaginário e ideário da modernidade, um processo que tem origem no século XVIII, fundamentais desdobramentos no século XIX e se consolida no decorrer do século XX.

Ainda que divertimentos, populares ou das elites, já sejam identificáveis em obras de períodos anteriores, é mesmo a partir do século XIX que o esporte vai progressivamente ser incorporado na produção artística de alguns países como a França e os Estados Unidos. No caso da Inglaterra, dada a sua condição de pioneira no encaminhar de uma parte significativa das mudanças relacionadas à modernidade, bem como liderança na organização e difusão do campo esportivo, não só a prática já estava presente nas obras do século XVIII, como se chegou a estabelecer um género denominado "pintura esportiva"(15). Tal presença não surpreende se considerarmos que arte e esporte compartilhavam de semelhante estrutura de sentimentos: uma nova dinâmica de tempos sociais, influência do modelo de produção fabril; a valorização da vida pública e das novas atividades de diversão nas cada vez maiores cidades; uma nova configuração da idéia de espetáculo, articulada com estratégias de indução do consumo.

Dado esse cenário, a investigação das relações entre arte e esporte parece ser útil para lançar um olhar não somente sobre os dois objetos como também sobre a própria ambiência sociocultural em que se inserem, ainda mais se tivermos em conta as provocações de Baudelaire(3): a modernidade, devido a sua contraditoriedade e complexidade, é uma ideia fundamentalmente construída em suas representações, na forma de espectáculo.

A ideia de espectáculo não se resume ao novo formato e presença social das diversões ou ao aumento da influência dos meios de comunicação, mas sim se trata de uma nova lógica de organização que paulatinamente vai marcar todas as instâncias sociais: a imagem vai cada vez mais se constituir no parâmetro central mediador da realidade. Arte e esporte estiveram plenamente inseridos e articulados com esse processo.
É compreensível que o esporte seja presença constante em obras inglesas, francesas e norte-americanas do século XIX e transição para o século XX, produzidas que foram em países que estavam na vanguarda do processo de mudanças, inclusive na arte. Também é inteligível que a prática esteja pouco representada na produção artística brasileira do fin de siècle. O Brasil passava por um conjunto similar de transformações, mas se encontrava em posição periférica, tinha que lidar com um grande conjunto de particularidades e só mais tardiamente sintonizar-seia mais profundamente com o que ocorria no cenário internacional. Se nesse país, na virada de séculos, o esporte já dava claros sinais de organização e popularidade, o campo artístico em grande medida ainda era refractário a certas inovações, inclusive na recusa do abandono dos chamados "temas nobres", entre os quais não se encontrava o esporte.

O caso de Portugal é intrigante. Ainda que esse país estivesse muito próximo do centro dos acontecimentos europeus que marcaram o século XIX e início do século $\mathrm{XX}$, tanto do ponto de vista geográfico quanto do ponto de vista das relações historicamente estabelecidas (especialmente com a Inglaterra e a França), praticamente não encontramos naquele momento obras de arte nas quais o esporte esteja representado. Porquê isso? Mais ainda, como pode isso nos ajudar a refletir sobre o esporte, a arte e o contexto sociocultural português na transição dos séculos?

Tendo em conta essas discussões, este estudo teve por objectivo discutir a presença do esporte na obra de Amadeo de Souza-Cardoso, um dos primeiros artistas portugueses que esteve sintonizado, com peculiaridades que serão discutidas no decorrer do artigo, com as vanguardas europeias do pré-Primeira Grande Guerra. Argumentamos que, por suas características, essa produção se constitui em uma boa chave de compreensão das relações entre a prática esportiva, a arte e a sociedade em Portugal na transição dos séculos XIX e XX.

Para alcance do objectivo, dialogamos com as compreensões de Peter Burke acerca da possibilidade de construir uma "história cultural da imagem" ou uma "antropologia histórica da imagem"(4). As obras de arte são entendidas como fontes históricas e não como ilustrações. Foi a partir delas que buscamos discutir não somente o que se refere ao tema, como 
também aquilo que diz respeito à forma e ao contexto, dialogando com outros indícios para escrutinar os sentidos e significados do esporte no cenário sociocultural da época, inclusive o que pode ter se constituído em motivação para o artista representá-lo. Para ter acesso às obras de Amadeo de SouzaCardoso, utilizei catálogos de sua produção, notadamente o organizado por Freitas, Alfaro e Rosa ${ }^{(6)}$, o mais completo sobre o artista até os dias de hoje. Enfim, esperamos que esse estudo seja mais um contributo para o que temos chamado de promoção de uma "arqueologia social" do esporte, uma prospecção de sua presença por entre as redes e teias sociais.

\section{PORTUGAL, O ESPORTE E A ARTE NA TRANSIÇÃO DOS SÉCULOS XIX E XX}

Depois de um período de grande agitação política, os reinados de D. Pedro V (1853-1861) e de D. Luís (1861-1889) foram marcados por uma tranquilidade maior, a despeito de algumas breves crises internas e de Portugal seguir muito dependente de outras nações europeias, notadamente da Inglaterra. Tal estabilidade, por motivos diversos, será abalada na década de 1890 , fazendo exponenciar as contradições da monarquia constitucional. Na verdade, desde a década de 1870, e mais fortemente nos anos 1880, republicanos e socialistas começaram a se organizar, fundando mesmo partidos políticos que gozaram de alguma popularidade, reputação e relevância de actuação.

O Ultimato de 1890, que se seguiu à participação limitada de Portugal na Conferência de Berlim (1885), definitivamente obliterou os intuitos portugueses no continente africano (o "Mapa Cor-deRosa") e desencadeou internamente uma onda de indignação contra a monarquia, considerada fraca para lidar com as questões internacionais. Portugal sentia os efeitos da crise que se abateu sobre a Europa na década de 1890, as dificuldades de participar do novo cenário internacional no âmbito da segunda vaga da Revolução Industrial e ainda tinha que internamente lidar com as reivindicações de uma crescente classe média de características urbanas. Naquele momento, já existiam iniciativas de industrialização, que vinham de meados do século XIX, mesmo que ainda em grande parte sob a responsabilidade de estrangeiros. Havia também uma rede fér- rea e de transportes já mais desenvolvida. As ideias liberais, que chegaram a Portugal nas décadas finais do século XVIII, mais claramente seguiam conquistando espaço e seus efeitos eram perceptíveis não somente na economia e na política, como também na educação, na música, na arquitectura, notadamente na literatura, também nas artes plásticas. Intelectuais e artistas preconizavam a necessidade de modernização do país (com destaque para a Geração de 1870, liderada, entre outros, por Eça de Queiroz). Eram perceptíveis as mudanças no âmbito dos costumes. É nesse cenário que se organiza o campo esportivo em Portugal, algo que não chega a surpreender: em outras localidades a instituição do esporte também teve forte relação com o crescimento de uma classe média urbana, com a industrialização, com o propagar de ideias liberais e o desenvolvimento de um pensamento científico, que contribuía para a emergência de maiores preocupações com a saúde e com a higiene. Como demonstra Manuela Hasse( 7 , se a princípio o sport, praticado pela nobreza e alta burguesia, correspondia "a hábitos e costumes ingleses, daí uma certa condescendência favorável à invasão de um novo elemento da cultura"1, logo "estudantes, empregados de escritório ou de comércio e operários da indústria" 2 estariam envolvidos: a prática popularizar-se-ia.

Não tardou para que ao seu redor fossem construídas representações que extravasavam a simples questão da diversão, ainda que essa dimensão seguisse importante e cada vez mais forte conforme melhor se estruturava uma indústria do entretenimento no país. Regeneração moral e física logo será considerada como uma das principais justificativas da importância do esporte para o progresso da nação.

Não surpreende que Ramalho Ortigão, um dos líderes da Geração de 1870, em seu livro "John Bull Depoimento de uma testemunha acerca de alguns aspectos da vida e da civilização inglesa" (1887), comente de forma crítica:

Deixamos perder a tradição dos nossos antigos jogos atléticos - a péla, a bola, a barra, as canas, a argolinha, o pato, a malha, a carreira - e não os substituímos por nenhum exercício correspondente. Não há uma carreira de tiro, nem uma sala de armas, nem um parque de ginástica. Não fazem excursões a pé, mochila às costas, [...]. Não remam, não caçam, não pescam, não esgrimem, não atiram ao alvo(2). 
Como lembra Ernesto Rodrigues(2), o resumo do capítulo XIX já expressa bem os contrastes que Ortigão estabeleceu entre a Inglaterra e Portugal no que se refere à valorização da prática de atividades físicas: “O 'atleticismo' na sociedade inglesa e a espinhela caída na burguesia de Lisboa. - O sedentarismo burocrático e a vida rural. - Acção do espiritualismo dos governos sobre a musculatura das raças". De outro lado, Rodrigues(2) lembra que Pinto Carvalho, em $1899^{3}$, faz um balanço bem mais positivo:

Hoje faz-se mais ginástica do que nunca, as praças de touros triplicaram, constituíram-se sociedades atléticas e cinegéticas; temos o ciclismo, as carreiras de tiro, o jogo de pau, as regatas, o pugilato, do box, tão amado de Ricardo III $e$ de Byron; nenhum dos que disputam os lauréis do chic, nenhum dos que se curvam aforçuradamente ao jugo tirânico da moda deixa de trazer na idéia a tineta de esgrimir o florete como Grisier, a espada com Saint-Georges, ou de atirar à pistola como Junot; metemos uma bala de carabina no alvo com a mesma perícia de um atirador aos pombos de Monte Carlo; entregamo-nos aos exercícios físicos com todo o fervor de nossas almas e de nossos nervos; [...].

Honramo-nos de possuir escola de toureio e velódromos, as grandes solenidades hípicas das corridas cavalares e 0 pedestreanismo - o diabo a quatro!

Vale a pena observar que Melo(14) demonstra que, nesse cenário de busca de modernização, bem precocemente e fartamente se estabeleceram relações entre o esporte e outra novidade que desembarcou em terras portuguesas nos anos finais do século XIX: o cinema. Por que o mesmo não se passou com as artes plásticas?

Uma das explicações para tal (não) ocorrência pode ser encontrada na própria formação do campo artístico português: "Apesar da boa qualidade e de uma certa originalidade da pintura portuguesa, sobretudo na segunda metade do século XIX, é necessário reconhecer a sua incapacidade para acompanhar as realizaçôes internacionais mais avançadas do tempo" (11, p.518). Segundo Pedro Lapa(8, p.27-37), em Portugal não só o modernismo foi ambíguo e de lenta assimilação, como futuramente, sob a égide da "Política do Espírito", conduzida por António Ferro, já no período Salazar, teria sido obliterado em sua expressão máxima ao ser instrumentalizado.
Desde os anos 1880, alguns artistas portugueses vinham contestando o academicismo, se aproximando do realismo e da crítica de costumes; destaca-se o nome de Rafael Bordalo Pinheiro e um grupo de caricaturistas ligados aos republicanos. Mas sinais mais claros de uma conexão com o modernismo, de busca de sintonia com as vanguardas artísticas, somente nos anos 1910 podem ser identificados em Portugal, bastante tardiamente se compararmos com outros países europeus. Entre os nomes importantes desse movimento devem-se destacar os de Almada Negreiros, Guilherme Santa-Rita, Eduardo Viana e Amadeo de Souza-Cardoso. Deve ainda lembrar-se os responsáveis pela modernização da literatura portuguesa, entre os quais Fernando Pessoa e Mario de Sá-Carneiro. Entre esses, Souza-Cardoso parece ter sido aquele que pela primeira vez na produção artística portuguesa representou de forma denotada o esporte.

\section{AMADEO DE SOUZA-CARDOSO E O ESPORTE}

Amadeo de Souza-Cardoso é o documento conciso da raça portuguesa no século XX (...). Pertence à guarda avançada na maior das lutas que é o pensamento universal (...). É a primeira descoberta de Portugal na Europa do século XX (Almada Negreiros, 1916) ${ }^{4}$.

Membro de uma família da burguesia rural, Amadeo nasceu em 1887 no lugar de Manhufe, freguesia de Mancelos, Amarante (na região norte do país) e desde cedo já manifestava o talento para a arte. Quando vai para Paris (1906), contudo, por sugestão do pai, preocupado com seu futuro profissional, dedica-se inicialmente a estudar arquitectura. Nessa ocasião se aproxima de alguns artistas portugueses que já viviam na capital francesa, envolvendo-se com a produção de caricaturas. Volta constantemente a sua cidade natal, lá se estabelecendo em definitivo em 1914, em função da $1^{a}$ Grande Guerra.

Em Paris, conforme foi tomando contacto com os movimentos artísticos e se envolvendo com o próprio frenesi da cidade daquele instante, Amadeo vai se afastando dos seus colegas portugueses, larga a arquitectura, abandona a caricatura; sua pintura vai adquirindo novos formatos. De acordo com Paulo Ferreira: 
Enquanto os artistas portugueses de sua geração continuavam cativados pelos impressionistas, ou se contentam, nas academias, com lições de mestres que ensinam uma arte já ultrapassada, Amadeo, homem do presente, interessa-se pelos mais recentes movimentos artísticos $(5, \mathrm{p} .12)$.

No final da década de 1900 se torna amigo de Amedeo Modigliani, se aproxima de Constantin Brancusi, e logo estará integrado no circuito artístico de vanguarda. Teve contato com o cubismo, expressionismo, abstracionismo, futurismo, mas: "em rigor, não integrou, como fundador, nenhum movimento específico do modernismo, no entanto conviveu com muitas de suas situações, operando algumas heterodoxas relações entre movimentos com princípios extremamente puristas"(8, p.27). Sua produção será marcada por se mover, se deixar influenciar, mas jamais por se enquadrar: "O lugar de enunciação de Amadeo é volúvel, protéico, complexo, superficial, híbrido, semi-periférico"(8, p.27)

Nos anos iniciais da década de 1910, Amadeo já estará próximo do casal Sônia e Roberto Delaunay, que lhe abrirá as portas do circuito internacional ${ }^{5}$. Exporá no Salão dos Independentes (Paris, $1911 \mathrm{e}$ 1912), na International Exhibition of Modern Art (Nova Iorque, 1913, primeira grande exposição da vanguarda mundial nos Estados Unidos), e no Primeiro Salão de Outono Alemão (na Galeria Der Sturm, Berlim, 1913). Será ainda convidado para uma exposição organizada pelos vorticistas, em Londres, ao fim não realizada em função dos conflitos bélicos. $\mathrm{O}$ artista expõe pela primeira vez em Portugal em 1916. A exposição intitulada "Abstracionismo" foi inaugurada no Salão de Festas do Jardim Passos Manuel, no Porto, indo depois para Lisboa, ambientada nas Salas da Liga Naval (Palácio do Calhariz). Em ambas as oportunidades, o escândalo foi geral; no Porto foi quase agredido; chovem críticas negativas: "Tudo irritava os visitantes: os títulos das obras, as colagens de espelhos e ganchos de cabelos, as formas abstractas, $o$ cubismo, o futurismo... e até mesmo os preços"(5, p.13). Ainda que Souza-Cardoso tenha sido o primeiro e praticamente único português a participar ativamente do cenário internacional das primeiras vanguardas artísticas, isso de forma alguma significou a perda de referências locais: sua obra é ao mesmo tempo universal e regional, internacional e portuguesa. Nesse sentido, pode-se entender uma obra como
"Avant la corrida" (c.1912)6. Se o diálogo com as vanguardas é flagrante, tanto o tema (as tradicionais touradas portuguesas) quanto as formas de representação não são exactamente estritamente modernas. Na verdade: "Essa pintura é um dos exemplos mais perfeitos do modo como Amadeo interpreta na época os movimentos de vanguarda, específico na escolha do tema, ousado na expressão global de velocidade e subtilíssimo no requintado uso da cor"(6, p.43).

E no que se refere ao esporte, em que obras Amadeo o teria incorporado? Que motivações estariam por trás desse interesse? Há algumas possíveis suposições. Podemos argumentar que vivendo numa Paris em que o fenómeno esportivo já era bastante popular desde o final do século XIX, o que inclusive chamou a atenção de outros artistas, Amadeo tenha tido contacto com a prática, dela se aproximando no mesmo quadro de interesse pelas coisas da modernidade. Efectivamente suas obras nas quais a prática esportiva esteve presente são de seus últimos anos na capital francesa; depois que voltou a Portugal, o tema não mais aparece em sua produção.

Outro argumento parece-me mais plausível, sem que seja necessário abandonar o anterior. As obras de Amadeo em que o esporte está presente surgem no momento em que se acirra sua relação com o futurismo. Lembremos que por ocasião da $1^{\mathrm{a}}$ exposição dos futuristas em Paris, em 1912, Amadeo conheceu e se tornou amigo de Umberto Boccioni e Gino Severini, superando uma desconfiança inicial com as propostas do movimento.

Essa influência é mesmo declarada por Amadeo em entrevista concedida a João Moreira de Almeida, para o jornal O Dia de 4 de Dezembro de 1916, quando literalmente cita o Manifesto Futurista número 9, de Marinetti(1, p.489): "Nós queremos uma arte viril, poderosa, anti-sentimental; nós cultivamos o optimismo regenerador, o formidável desejo de aventura, a paixão do Sport, a adoração dos músculos, a coragem física e moral". Melo(12) já demonstrou que a prática esportiva não só foi tema constante na produção dos futuristas (italianos e seus desdobramentos na Rússia e Inglaterra, entre outros), como dialogava profundamente com as próprias propostas teóricas do movimento, com as ideias-chave de combate à tradição, valorização do urbano e das massas, elegia da velocidade e do combate. Isso pode ter sido um determi- 
nante, ao menos forte influência, no olhar que o português começou a lançar sobre o esporte.

Tal influência parece explícita em "Desenho Futurista (movimento)" (c.1912)7 . Ao fundo, vemos uma grande cidade, retorcida pelo acúmulo de construções, mas também pela velocidade dos veículos que aparecem em primeiro plano; nela vemos alguns símbolos-chave da modernidade: chaminés, pontes, indústrias, aviões. Em primeiro plano, ocupando a parte inferior, há uma carruagem, conduzida por um indivíduo de cartola, sendo ultrapassada por duas bicicletas (ou uma bicicleta e uma motocicleta) e três automóveis, dois deles mais modernos e conduzidos por indivíduos com vestimentas mais "atuais" (um deles por duas mulheres, uma novidade à época). Os animais, notadamente o cavalo, parecem assustados com a velocidade das rodas, algo enfatizado pelo uso de espirais.

Trata-se de uma bela representação da vida moderna e de seus novos símbolos, muitos dos quais constantemente celebrados pelos futuristas. O contraste entre os carros e os cavalos lembra a gravura "Automóvel e a caça da raposa", de Umberto Boccioni (1904) ${ }^{8}$. A composição da cidade parece inspirada nas composições arquitetônicas dos italianos ${ }^{9}$. O uso da espiral para expressar os movimentos era também comum entre os italianos; podemos citar, por exemplo, "Motociclista" (Gerardo Dottori, 1914) 10 e "Velocidade de uma motocicleta"

(Giacomo Balla, 1913) ${ }^{11}$.

Por que o tema dessa obra pode ser relacionado ao esporte? Devemos ter em conta que naquele momento, para além de sua dimensão de competição, como lembra Sevcenko(17, p.558):

Era como uma modalidade esportiva que os carros eram encarados em sua primeira aparição na cena urbana, importados pelos novos protagonistas sociais, o que contribuiu de forma decisiva para sua instantânea identificação com o clímax da modernidade ${ }^{12}$.

Souza-Cardoso representou outros esportes "menos tecnológicos", mais comummente pintados pelos artistas do século XIX. Uma de suas primeiras aproximações com o turfe foi produzida também em 1912, uma obra sem título em que representa um conjunto de jóquei e cavalo em pleno movimento ${ }^{13}$.
A economia de linhas lembra sua relação com Modigliani, mas o movimento das patas, do corpo do animal e da cabeça do jóquei são um claro flerte com a ideia de simultaneidade dos futuristas; o uso de cores é forte, mas elegante e sutil como no já citado "Avant la corrida". No mesmo ano, ainda sob influência dos futuristas, mas esteticamente estabelecendo fortes relações com o cubismo, Amadeo pintou "Jockey" (c.1912)14, uma obra que tem relação com uma das suas paixões: a cor. Helena de Freitas(6, p.89) afirma que:

Em resumo e simplificando, poderá dizer-se que Amadeo na sua interpretação do cubismo foi heterodoxo (sobretudo) na dinâmica do espaço, na liberdade temática e na utilização assumida do movimento e da cor. Mas nesse contexto foi acompanhado por muitos outros artistas com quem a sua obra se pode cruzar. Remeto pontualmente para as pinturas de Lyonel Feininger, The Bicycle Race (1912), em articulada leitura com o Jockey de Amadeo, e da artista russa Olga Rozanova, Homem na rua-análise de volumes (1913), de expressão cubo-futurista.

A relação estabelecida por Freitas com a obra "A corrida de bicicletas", de Lyonel Feininger (1912) ${ }^{15}$, é para nós muito relevante. A representação de jóqueis é algo muito comum na história da arte desde o século XVIII. Entre tantas obras, todavia, nada se assemelha ao que faz Amadeo: o personagem central parece um misto de jóquei e ciclista, a meio do caminho entre a tradição e a modernidade. Seria exagerado supor que isso se deve a sua condição de pintor português? Pode ser que sim, mas se tivermos em conta os olhares antes discutidos, essa é uma consideração plausível.

A impressão de que o cavaleiro é um ciclista estilizado fica ainda mais forte quando vemos "Os cavaleiros" (c.1913)16. Entre os múltiplos planos e círculos que compõe a tela, em um quadro em que figura e abstracção praticamente se confundem, em que não se pode precisar onde estão os planos cubistas ou as linhas de força futuristas, cavalo e bicicleta/jóquei e ciclista parecem se confundir em meio a um frenesi de cores que deixa vislumbrar alguns rostos anónimos. A ideia de movimento é impressionante; há uma clara sintonia com o contexto de sua produção: 
A pulsão de Amadeo pela ideia de movimento presente desde cedo no seu trabalho (...) é rapidamente absorvida no decurso dessas experiências, não certamente alheia à implosão ruidosa dos futuristas, mas sobretudo por expressão própria (...) Barcos e Cavaleiros são exemplos de soluções espaciais evolutivas da linguagem cubista, mas que em definitivo escapam ao seu convencial imobilismo(6, p. 37).

Para concluir, falemos de dois quadros de mesmo nome, lançados em anos sucessivos. Em grande medida essas obras sintetizam as características do artista: uma sintonia com as vanguardas, mas a busca de um olhar próprio, um olhar universal que dialoga com o local, dimensões que ajudam a entender o hibridismo de sua produção.

"O atleta" (c.1912)17 dialoga mais claramente com as propostas de Modigliani e Brancusi, destacandose pela economia de formas e a proximidade com artes arcaicas e exóticas: um misterioso personagem segura uma barra de halteres, encarando frontalmente o espectador. Na verdade, "o carácter satírico do desenho atenua-se perante o pathos de movimentos que despontam e o jogo formal, ritmicamente imbricado"(18, p.381). Já "O atleta” (c.1913)18, que participou do Salão de Outono da Galeria Der Sturm/Berlim, hoje de paradeiro desconhecido, é uma representação corpórea próxima do modelo dos futuristas, ainda que não se perceba o uso de linhas de força concêntricas, o que também a aproxima dos cubistas. Não se conhece a composição das cores, mas pelos comentários sabese que se aproximava do que era comum entre os cubofuturistas russos.

A obra parece mesmo uma espécie de síntese criativa das propostas que geraram, por exemplo, "Dimensões de um jogador de futebol” (Boccioni, 1913) ${ }^{19}$, e "Boxeador" (Pablo Picasso, 1912)20. Sobre ela, comenta Marcadé(10, p.434): "Se menciono Der Athlet (...) é porque nos mostra um artista que atingiu o pleno controlo da sua arte. Esse quadro (...), que o artista considerava seu talismã, é um magnífico exemplo de cubofuturismo".

\section{À GUISA DE CONCLUSÃO}

Amadeo de Souza-Cardoso serviu bem muitas das vontades míticas por cá existentes entre a genialidade precoce, vertiginosa e finalmente desentendida pela pertença periférica do artista, e as apressadas qualificações da obra como um epi- gonismo voraz e pouco mais. Amadeo oscilou, nestas qualificações e desqualificações, (...) como se essas variáveis tipológicas tão portuguesas e tão universais pudessem trazer ao menos réstia de luz para entender a obra(16, p. 15).

Segundo Pedro Lapa, Souza-Cardoso é uma clara expressão de Portugal:

Entre signos de uma cultural local (...) e os de uma cultura de vanguarda transnacional (...) manifesta-se uma hibridez característica dessa cultura de fronteira. A facilidade em articular uma especificidade local (regional) com um contexto internacional, centralista e hegemônico, é um claro exemplo dessa característica nacional (8, p. 34-36).

O autor lembra que Boaventura de Sousa Santos afirma que Portugal nunca foi constituído categoricamente, a não ser como zona fronteiriça; seus artistas, assim, constantemente tiveram que se perguntar sobre sua identidade. Isso parece claro em Amadeo de Souza-Cardoso:

O que sua condição lhe possibilitou foi uma distância em que tudo está próximo e ao mesmo tempo afastado. Daí que os enfoques e a reescrita dos fenômenos os possa devolver a si próprios numa determinada contingência. Com isto Amadeo abre o caso português do século $X X^{(8, p .34-36)}$.

O que mais nos interessa é pensar como esse autor "semi-periférico" acaba por "Demonstrar como no mesmo contexto histórico-cultural podem surgir outras alteridades que, em vez de especificidade pretensamente universalizante, especificam um dado entendidamente da universalidade, que assim se revela contingente"(8, p.34-36). Nesse sentido, a produção de Amadeo ajuda a pensar nas hibridações, nas projeções e visões alternativas de modernidade e no próprio conceito de periferia; fundamentalmente nas estratégias de construção de uma imagem para os países/localidades que de alguma forma se encontram à margem.

Não surpreende, assim, que na obra de Amadeo o esporte tenha sido tratado, tanto do ponto de vista da forma quanto do tema, a partir do diálogo entre o global e o local, expressão das peculiaridades que compõem o moderno em Portugal: suas composições imagéticas ressignificam uma certa directriz cujo vector vem do centro; como os outros elementos cul- 
turais, também a margem deixará marcas na sua organização peculiar (aqui vista pela representação) da prática esportiva.

Esse estudo, portanto, chama a atenção para a articulação de dois importantes elementos. Voltando a Baudelaire, já citado na introdução, e sua posição acerca da importância das representações para a ideia de modernidade, é preciso prospectar, dentro desse cenário complexo de periferia-centro, onde as posições não são estanques e as inter-influências são múltiplas, como o esporte foi elemento activamente partícipe, na mesma medida em que expressou um conjunto de imagens específicas de uma nação, ou melhor, de uma cultura. Por certo isso tem grande relação com a identidade, ou se quisermos ser mais rigorosos, com a invenção de tradições que compõe os discursos identitários de países.

Aqui entra o outro elemento. Em certa medida, a experiência de Portugal não é exclusiva desse país, mas expressa algo da lusofonia como um todo, marcada nos últimos séculos pelas já citadas noções de periferia e hibridismo. Assim sendo, parece interessante insistir na prospecção de elementos que possam contribuir para o traçar de análises comparadas, ampliando as compreensões sobre as nossas semelhanças e dissemelhanças, algo que pode ampliar nosso entendimento sobre nossas histórias nacionais, mas também sobre a cultura lusófona no mundo; postura importante inclusive para que possamos aperfeiçoar nossa alianças, fundamentais no cenário geopolítico internacional. Parece que podemos contribuir com esses esforços a partir do caso específico do esporte.

Isso será fundamental até mesmo para que encontremos espaços de poder mais confortáveis, para que possamos reverter algo pelo qual passou o próprio Souza-Cardoso:

Amadeo foi sempre visto como a maior das promessas, mas também como dificilmente integrável nas ortodoxias parisienses, que por muito tempo balizaram a história da arte; as aproximações aos cubismos, que foram diferentes entre si, levavam-no a ocupar uma posição dependente e por isso menor, enquanto aos rasgos de originalidade faltava a maturação de um percurso mais longo. Uma forma muito nacional de inferioridade foi menorizando o que se apresentava como mais pessoal e interpretando como influências sofridas (de Modigliani, de Brancusi, por exemplo) o que era cumplicidade e concorrência criativa, ou mesmo influência exercida sobre outros(9).

O seguimento dos estudos e investigações parece ser apontamento necessário e saudável para aqueles que pretendem encarar o esporte não como uma ilha solta no oceano, mas sim como um fenómeno social eivado das tensões de seu tempo: aí está o seu grande valor enquanto objecto de investigação.

\section{AGRADECIMENTOS}

Ao Conselho Nacional de Desenvolvimento Científico e Tecnológico (CNPq)/Brasil (bolsa de produtividade) e à Fundação de Amparo à Pesquisa do Estado do Rio de Janeiro/Faperj (apoio a grupos emergentes e apoio Jovem Cientista de Nosso Estado), pelo auxílio financeiro concedido para a realização deste estudo.

À Biblioteca de Arte da Fundação Calouste Gulbenkian, notadamente à Sra. Ana Barata, pelo apoio à realização da investigação.

\section{CORRESPONDÊNCIA}

Victor Andrade de Melo

Praia de Botafogo, 472/810 - Botafogo - Rio de

Janeiro - RJ

CEP: 22250-040

E-mail: victor.a.melo@uol.com.br 


\section{NOTAS}

${ }^{1}$ página 306.

2 página 306.

3 A passagem de texto acima citada por Rodrigues refere-se à seguinte publicação: PINTO DE CARVALHO (Tinop). Lisboa d'outros tempos, II, Os Cafés, 1899. Edição fac-similada, Lisboa: Fenda Edições, 1991, p.248-249.

${ }^{4}$ Em folheto publicado por ocasião da exposição "Abstraccionismo”, realizada nas cidades do Porto e Lisboa em 1916. ${ }^{5}$ No período de guerra, o casal morou em Portugal e teve grande influência nos primórdios de estruturação de uma vanguarda artística no país.

${ }^{6}$ Óleo sobre tela, 60 × $92 \mathrm{~cm}$. Acervo do Centro de Arte Moderna José de Azeredo Perdigão/Fundação Calouste Gulbenkian/Lisboa. Disponível em: http://www.camjap.gulbenkian.pt/11/ar\%7B178A24AD-5CED-43ed-9211-7964C86D2B7F $\% 7 \mathrm{D} / \mathrm{ml} / \mathrm{t} 1$.aspx. Acesso: 1 de Dezembro de 2008.

${ }^{7}$ Grafite sobre papel, 26 x 33,5 cm. Acervo de Museu Municipal Amadeo de Souza-Cardoso/Amarante. Disponível em: http://www.amarante.pt/museu/coleccoes.php?pagina=1\&tipo $=1$. Acesso: 1 de Dezembro de 2008 .

${ }^{8}$ Gravura colorida. Acervo de Automobile Club d'Italia.

Disponível em: http://www.aci.it/index.php?id=331. Acesso: 1 de dezembro de 2008.

${ }^{9}$ Por exemplo: de Boccioni, “A strada entra nella casa" (1911). Óleo sobre tela, 100 x 100,6 cm. Acervo de Sprengel Museum Hannover. Disponível em: http://www.sprengel-museum.de/v1 /englisch/02munds/boccioni/ub_ls_a.html. Acesso: 1 de Dezembro de 2008.

${ }^{10}$ Pastel e têmpera sobre papel, 25 x $36 \mathrm{~cm}$. Colecção particular. Disponível em: http://www.futur-ism.it/collezioni/opere/ opere.asp? aut $=14 \&$ page $=1$. Acesso: 1 de Dezembro de 2008 . 11 Óleo sobre tela. Acervo de Hermitage Museum/São Petesburgo . Disponível em: http://www.hermitagemuseum. org/html_En/04/2005/hm4_1_97_1.html. Acesso: 1 de Dezembro de 2008.

12 Para mais informações, ver estudo de Melo (13).

${ }^{13}$ Aquarela sobre papel colado sobre cartão, 23,8 x 33,3 cm. Acervo do Centro de Arte Moderna José de Azeredo Perdigão /Fundação Calouste Gulbekian/Lisboa. Disponível em: Freitas, Alfaro e Rosa (2006).

14 Óleo sobre tela, 61 x $50 \mathrm{~cm}$. Acervo do Centro de Arte Moderna José de Azeredo Perdigão/Fundação Calouste Gulbekian/Lisboa. Disponível em: Freitas, Alfaro e Rosa (2006). 15 Óleo sobre tela, 80,3 x 100,3 cm. Acervo de National Gallery of Art/Washington. Disponível em: http://www.nga.gov/fcgibin/tinfo_f?object $=66415$. Acesso: 1 de Dezembro de 2008 . 16 Óleo sobre tela, 100 x $100 \mathrm{~cm}$. Acervo de Museé National de Arte Moderne/Centre Georges Pompidou/Paris. Disponível em: http://www.centrepompidou.fr. Acesso: 1 de Dezembro de 2008. 17 Tinta da china e guache sobre papel, $32,5 \times 25 \mathrm{~cm}$. Acervo do Centro de Arte Moderna/Fundação Calouste Gulbekian/Lisboa. Disponível em: Freitas, Alfaro e Rosa (2006).

${ }_{18}$ Colagem e tinta esilográfica sobre cartão, $23,8 \times 17,8 \mathrm{~cm}$. Acervo do Centro de Arte Moderna/Fundação Calouste Gulbenkian/Lisboa. Disponível em: http://www.camjap.gulbenkian.pt/12/ ar\%7B178A24AD-5CED-43ed-9211-7964C86D2B7F\%7D/m1/ t1.aspx. Acesso: 1 de Dezembro de 2008.

19 Óleo sobre tela, 193,2 x $201 \mathrm{~cm}$. Acervo do Museum of Modern Art/Nova Iorque. Disponível em: http://www.moma.org. Acesso: 1 de Dezembro de 2008. 20 Oleo sobre tela. Acervo do Centre for Modern and Contemporary Art, Veletrzni (Trades Fair) Palace/ Praga. Disponível em: http://www.flickr.com/photos/ 37804979@N00/2558172685. Acesso: 21 de Julho de 2008.

\section{REFERÊNCIAS}

1. Alfaro C (2006). Biografia de Amadeo de Souza-Cardoso: 1887-1918. In: Freitas H, Alfaro C, Rosa M (eds.), Amadeo de Souza Cardoso: diálogo de vanguardas. Lisboa: Fundação Calouste Gulbenkian/ Centro de Arte Moderna José de Azeredo Perdigão, pp.429-496

2. apud Rodrigues E (2004). Jogos de letras. Disponível em: http://culturaport.blogs.sapo.pt/arquivo/170255.html. Acesso: 2 de Novembro de 2008

3. Baudelaire C (1996/1869). Sobre a modernidade. Rio de Janeiro: Paz e Terra.

4. Burke P (2004). Testemunha ocular: história e imagem. Bauru: Edusc.

5. Ferreira P (1987). Amadeo de Souza-Cardoso, a ânsia de criar. In: Fundação Calouste Gulbekian. Centenário do nascimento de Amadeo de Souza-Cardoso. Lisboa: Fundação Calouste Gulbenkian, 1987, pp.11-13

6. Freitas H (2006). Amadeo de Souza-Cardoso, diálogo de vanguardas. In: Freitas H, Alfaro C, Rosa M (eds.), Amadeo de Souza Cardoso: diálogo de vanguardas. Lisboa: Fundação Calouste Gulbenkian/ Centro de Arte Moderna José de Azeredo Perdigão, p.20-70

7. Hasse M (1999). O divertimento do corpo - corpo, lazer e desporto na transição dos séculos XIX e XX, em Portugal. Lisboa: Temática, pp.305-306

8. Lapa P (2001). Amadeo de Souza-Cardoso, a memória de um presente distante. In: Museu do Chiado. Amadeo de Souza-Cardoso: um pioneiro do modernismo em Portugal. Lisboa: Museu do Chiado, 2001, pp.27-37

9. Loescher RJ (2000). A Neglected Modernist - Amadeo de Souza Cardoso. Disponível em

http://findarticles.com/p/articles/mi_m1248/is_9_88/ai_650695 37. Acesso: 1 de Dezembro de 2008 .

10. Marcadé JC (2006). Souza-Cardoso e o Cubofuturismo vindo da Rússia. In: Freitas $\mathrm{H}$, Alfaro C, Rosa M (eds.), Amadeo de Souza Cardoso: diálogo de vanguardas. Lisboa: Fundação Calouste Gulbenkian/ Centro de Arte Moderna José de Azeredo Perdigão, pp.363-378

11. Marques AHO (2005). Breve história de Portugal. Queluz de Baixo: Presença: pp. 518.

12. Melo VA (2007). Esporte, Futurismo e modernidade. História, 26(2): 201-225.

13. Melo VA (2008). O automóvel, o automobilismo e a modernidade no Brasil (1891-1908). Rev. Bras. Ciênc. Esp., 30(1): 57-69

14. Melo VA (2008). O esporte no cinema de Portugal. Rev Port Cienc Desp, 8(1): 157-168

15. Melo VA (2009). Esporte, lazer e artes plásticas: diálogos. Rio de Janeiro: Apicuri/Faperj. no prelo.

16. Molder J (2006). Entrada. In: Freitas H, Alfaro C, Rosa M (eds.), Amadeo de Souza Cardoso: diálogo de vanguardas. Lisboa: Fundação Calouste Gulbenkian/ Centro de Arte Moderna José de Azeredo Perdigão, pp.13-18

17. Sevcenko N (1998). A capital irradiante: técnica, ritmos e ritos do Rio. In: Sevcenko N (org.). A história da vida privada no Brasil: da Belle Époque à era do rádio. São Paulo: Companhia das Letras, pp.513-620

18. Waldegg JHV (2006). Amadeo de Souza-Cardoso, Otto Friendlich e o expressionismo alemão. In: Freitas H, Alfaro C, Rosa M (eds.), Amadeo de Souza Cardoso: diálogo de vanguardas. Lisboa: Fundação Calouste Gulbenkian/ Centro de Arte Moderna José de Azeredo Perdigão, pp.379-412 